\title{
Psychological essentialism and the differential attribution of uniquely human emotions to ingroups and outgroups
}

\author{
JACQUES-PHILIPPE LEYENS, ${ }^{1 *}$ \\ ARMANDO RODRIGUEZ-PEREZ, ${ }^{2}$ \\ RAMON RODRIGUEZ-TORRES, ${ }^{2}$ \\ RUTH GAUNT, ${ }^{1}$ MARIA-PAOLA PALADINO, ${ }^{1}$ \\ JEROEN VAES ${ }^{1}$ AND STÉPHANIE DEMOULIN ${ }^{1}$ \\ ${ }^{1}$ Université Catholique de Louvain, Louvain-la- \\ Neuve, Belgium \\ ${ }^{2}$ Universidad de La Laguna, Tenerife, Canary Islands
}

\begin{abstract}
According to the psychological essentialism perspective, people tend to explain differences between groups by attributing them different essences. Given a pervasive ethnocentrism, this tendency implies that the human essence will be restricted to the ingroup whereas outgroups will receive a lesser degree of humanity. Therefore, it is argued that people attribute more uniquely human characteristics to the ingroup than to the outgroup. The present article focuses on secondary emotions that constitute such characteristics. Study 1 showed that members of high-and low-status groups attribute more positive secondary emotions to the ingroup than to the outgroup. Study 2 verified that the differential attribution extended also to negative secondary emotions. No exemplars of emotions were provided in Study 3. Instead, participants had to estimate the means of two distributions of numbers that supposedly represented characteristics of the ingroup and of the outgroup. The results of this third experiment illustrated the reluctance to attribute secondary emotions to the outgroup. The findings are discussed from the perspective of psychological essentialism. Copyright (C) 2001 John Wiley \& Sons, Ltd.
\end{abstract}

Very often, patriotism is at the roots of wars. Allport (1927) agreed with this view and gave it a psychological explanation. For him, attachment to one's group becomes a cause of war because of the nationalistic fallacy. By this expression, Allport meant the false belief that the group-nation goes beyond the mere collection of individuals. Social psychologists know by now that groups cannot be reduced to the simple association of individuals (e.g. Sherif \& Sherif, 1964). They also know that people tend to infuse an essence (biological, cultural, religious, etc.) into social groups in order to explain their differences (e.g. Hirschfeld, 1996; Rothbart \& Taylor, 1992). It is likely that Allport

*Correspondence to: Jacques-Philippe Leyens, Université Catholique de Louvain at Louvain-la-Neuve, UPSO, Place Cardinal Mercier 10, 1348 Louvain-la-Neuve, Belgium. E-mail: leyens@upso.ucl.ac.be

Copyright (C) 2001 John Wiley \& Sons, Ltd.

Received 23 June 2000

Accepted 13 November 2000 
(1927) attacked the notion of group-nation because of his fear of a group's mind that would correspond to the essence of the group.

In the present paper, we review the essentialist concept as it applies to racism. We suggest that people attribute the human essence to their group, and a lesser degree of humanity to the outgroup. We then outline what should be considered 'the' human essence. We hypothesize that people attribute more uniquely human characteristics to the ingroup than to outgroups. Our studies focus on secondary emotions, which constitute uniquely human characteristics. Using two different paradigms, we test in three studies the hypothesis that members of both dominant and dominated groups will attribute more secondary emotions to their ingroup than to a disliked dominant or dominated outgroup.

\section{ESSENTIALISM AND RACISM}

Psychological essentialism perspective suggests that people tend to endow social groups with essences (Haslam, Rothschild, \& Ernst, 2000; Rothbart \& Taylor, 1992). By attributing essences to groups, people believe that they can define the very nature of these groups. The essence is supposed to identify those elements that unite members into an entitative coherent group (Campbell, 1958; Miller \& Prentice, 1999; Yzerbyt, Rocher, \& Schadron, 1997), as well as those elements that distinguish one's group from other groups.

In their discourses, dominant as well as dominated groups very often resort to an essentialist view. Dominant groups use it to legitimize their superiority. Dominated groups also invoke an essence to explain their inferior status and justify their claims (Jost \& Banaji, 1994; Sidanius \& Pratto, 1999). In addition, numerous studies have illustrated people's general tendency to favor their ingroup over outgroups (for reviews, see Brewer \& Brown, 1998; Leyens, Yzerbyt, \& Schadron, 1994; but see Heine \& Lehman, 1997). If people are ethnocentric and are mainly concerned with the wellbeing of their ingroup, and if they attribute essences to groups to explain their differences, they will attribute 'the' human essence to their ingroup. It follows that, if people make an essentialist distinction between their ingroup and outgroups, these outgroups can receive only an infra-human essence (Leyens, Paladino, Rodriguez, Vaes, Demoulin, Rodriguez, \& Gaunt, 2000). Thus, it is argued that both dominant and dominated groups will restrict to their members the defining characteristics of 'the' human essence.

It follows from this reasoning that not every group will give an infra-human essence to any other group. Such an infra-human essence will be attributed only to the extent that one group believes that it has 'the' human essence and that the other group is fundamentally different. In exceptional cases (e.g. slavery or colonialism), it may even happen that groups internalize the inferiority attributed by the outgroup and that they think of themselves as infra-humans.

We propose that people will attribute to themselves those characteristics that are considered uniquely human. These characteristics are necessary to constitute the human essence. We also hypothesize that in some cases an outgroup composed of 'others' will be credited with less human characteristics than the ingroup. Stated otherwise, the outgroup will lack some uniquely human characteristics and receive an incomplete human essence, or an infra-human essence (Leyens et al., 2000).

\section{WHAT IS THE HUMAN ESSENCE?}

Asked to list the uniquely human characteristics, several samples of Latin-language-speaking students answered: intelligence, reasoning, sentiments, and language (Leyens et al., 2000). There is already an 
abundant literature showing that intelligence, reasoning and language are correlated and are used to discriminate against outgroups (e.g. Bourhis \& Leyens, 1994). We therefore decided to focus our attention on sentiments. It is also an original way to re-introduce emotions in the domain of intergroup relations.

The distinction between sentiments and émotions needs some explanation. ${ }^{1}$ It exists in Latin languages and, to a lesser degree, in Germanic languages, but has no equivalent in English. This lingual distinction corresponds both to a lay concept of emotions and to the classification of emotions in the scientific literature. In the lay concept, whereas even animals have émotions, sentiments are uniquely human. In the scientific literature, the distinction between sentiments and émotions corresponds to the distinction between primary and secondary emotions. Primary emotions are biologically based and shared by other primates; they have a quick onset, a short duration and their occurrence is unbidden; they also appear early in life (Ekman, 1992; Sroufe, 1979). Secondary emotions result from the attachment of new labels to various aspects of social interactions (Kemper, 1987); often, they are a composite of primary emotions (Johnson-Laird \& Oatley, 1989; Plutchik, 1994). Although disagreements exist concerning their precise number, six primary emotions (anger, surprise, fear, joy, sadness, and disgust) are most commonly cited (for a review, see Plutchik, 1994). Examples of secondary emotions are sorrow, admiration, fondness, disillusion, contempt, conceit, etc. Whereas the scientific view of emotions makes a dichotomous distinction between a few primary and many secondary emotions, the lay conception envisions emotions on a continuum going from many 'uniquely human' to many 'non-uniquely human' emotions. In preliminary studies French-speaking, Spanish-speaking, Dutch-speaking, and American English-speaking participants had to rate different emotional terms on several characteristics (Demoulin, Leyens, Paladino, Rodriguez, Vaes, Dovidio, \& Rodriguez, 'Dimensions of typically and non-typically human emotions', in preparation, 2000). The results showed a similar pattern across samples. Stated otherwise, people view emotions in a similar manner independently of the fact that they have different (or no) labels to categorize them. Sentiments or 'uniquely human' emotions are more specific to human beings, have a longer duration, are less intense, involve more morality, cognition and sensitivity, are less visible, appear later in life, and are more internally caused than émotions, or 'non-uniquely human' emotions. Moreover, compared to sentiments, émotions vary less as a function of culture. These results show a clear correspondence between sentiments and secondary emotions, on the one hand, and between émotions and primary emotions, on the other. Therefore, we will use the distinction between primary versus secondary emotions in the present paper.

\section{DIFFERENTIAL ATTRIBUTIONS OF SECONDARY EMOTIONS TO INGROUPS AND OUTGROUPS}

A first set of studies using the implicit association task (Greenwald, McGhee, \& Schwartz, 1998) already tested the differential associations between primary and secondary emotions, on the one hand, and ingroup and outgroup, on the other (Paladino, Leyens, Rodriguez, \& Rodriguez, 'Differential associations of internally and externally referred emotions with ingroup and outgroup', in preparation, 1999). Indeed, if uniquely human characteristics are all necessary to be a human being, people should more easily associate their ingroup (i.e. French or Spanish names depending on the study) with secondary emotions, and an outgroup (i.e. North African names) with primary emotions (the

\footnotetext{
${ }^{1}$ Before proposing the taxonomy of secondary and primary emotions, we will use the French terms sentiments and émotions, meaning uniquely human emotions and non-uniquely human emotions.
} 
compatible task), than the reverse (the incompatible task). In two experiments the emotions were all positive; in a third, they were all negative. As expected, participants took significantly more time for the incompatible task than for the compatible one, and the size effects of the IAT indices were quite large. Differential associations of secondary and primary emotions, however, are insufficient to test precisely our thesis. Indeed, we would like to attribute the difference to the special link between the ingroup and the secondary emotions, but the implicit association task (Greenwald et al., 1998) does not yet allow to isolate the responsible factor.

If people attribute a lesser humanity to disliked outgroups than to their ingroup, they should also spontaneously attribute more uniquely human characteristics to the ingroup than to an outgroup. It has been previously shown that dominant groups tend to feel superior in intelligence and language than dominated groups (e.g. Bourhis \& Leyens, 1994; Crocker, Major, \& Steele, 1998). There is no available evidence that secondary emotions are specific to high-status or to low-status groups (Fiske, Xu, Cuddy, \& Glick, 1999; Glick \& Fiske, 1999). Therefore, we hypothesize that members of both high- and low-status groups will spontaneously attribute more secondary emotions to the ingroup than to the outgroup. It should be noted that, because secondary emotions in general are considered uniquely human characteristics, the greater attribution of secondary emotions to the ingroup should be independent of the valence of these emotions (see Paladino et al., 1999). Stated otherwise, the differential attribution of positive and negative secondary emotions to the ingroup and to the outgroup reflects a lack of uniquely human characteristics in the outgroup.

No clear prediction can be made about primary emotions. Because this kind of emotion is not uniquely human, it does not distinguish between the ingroup and the outgroup, and thus one could expect no difference of attribution. However, because of the ingroup favoritism bias (e.g. Brewer \& Brown, 1998; Leyens et al., 1994), it may well be that the attribution of primary emotions will depend on their valence and that more positive primary emotions will be attributed to the ingroup than to the outgroup.

\section{OVERVIEW OF THE STUDIES}

In Study 1, members of high- and low-status groups received a list of items comprising exemplars of positive primary and secondary emotions. Their task was to check the items that defined either their group or the outgroup.

Study 2 replicated Study 1 with two major exceptions. Other positive primary and secondary emotions were used for the sake of generalizability. Also, the list contained negative primary and secondary emotions to verify that the differential attribution of secondary emotions was independent of their valence.

No exemplars of emotions were provided in Study 3. Following a paradigm innovated by Krueger, Rothbart, and Sriram (1989), participants had to calculate on-line the mean of numbers representing the degree of calcium, of primary emotions, or of secondary emotions of the ingroup and of the outgroup. Calcium served as a base-line because it was irrelevant for the participants.

\section{STUDY 1}

Students from the Canary Islands and from mainland Spain (Peninsula) participated in the experiment. In general, Canarians resent the dominating role of Peninsulars and stereotype themselves as more 
likeable. Peninsulars, on the other hand, tend to look down on Canarians and view themselves as more competent than Canarians. There is thus a conflicting situation on the part of the lower-status group (i.e. the Canarians) and some kind of outgroup derogation on the part of the higher-status group (i.e. the Peninsulars). To preclude the criticism that Peninsulars were represented by only one region of the country, we decided to test two different groups of Peninsulars - Castillans from Madrid and Catalans from Barcelona.

Each participant received a list comprising 16 stimuli: four positive secondary emotions, four positive primary emotions, four traits linked to competence, and four traits linked to niceness (Fiske et al., 1999; Glick \& Fiske, 1999). Competence and niceness traits were treated as fillers. The valence of the stimulus words had been pre-tested and controlled. Participants had to select the words that were necessary to define a Canarian or a Spanish from the mainland (Peninsulars). This paradigm was borrowed from Yzerbyt and Castano's (1999, unpublished manuscript) investigation of ingroup overexclusion (Leyens \& Yzerbyt, 1992; Yzerbyt, Leyens, \& Bellour, 1995). In accordance with our theory (Leyens et al., 2000), we expected that both groups would attribute more secondary emotions to their ingroup than to the outgroup. No prediction was made concerning the attribution of primary emotions.

Competence and niceness were included as filler traits to prevent an exclusive focus on emotional terms and to provide material to test Fiske et al.'s (1999) taxonomy. However, their analyses will not be reported in the present paper in order not to distract the attention from our main purpose.

\section{Method}

\section{Participants}

Seventy-two students at the University of La Laguna in Tenerife, 90 students at the Computense University of Madrid, and 99 students at the Autonoma University of Barcelona took part in the study as part of an exercise during their classes.

\section{Procedure}

Each student received a small booklet that listed a series of 16 words in random order. Four were secondary emotions ${ }^{2}$ (nostalgia, nostalgia; compasión, compassion; orgullo, pride; and arrepentimiento, remorse). Four were primary emotions (coraje, courage; asombro, astonishment/fear; exaltación, exaltation; and sorpresa, surprise). Pre-tests with 10-point scales were run so that there would be no difference of valence between the primary and secondary emotions. Secondary emotions $(M=6.81)$ were not significantly different from primary ones $(M=6.48), t(15)=0.88, n s$. The eight other words were fillers, related to competence and niceness. Their valence was also controlled so that there would be no difference between the niceness and competence traits. Half of the participants in each university had to select from the list of words those that they considered typical characteristics of

\footnotetext{
${ }^{2}$ The selection of primary and secondary emotions was based on both the emotions' valence and the prototypicality of their categories. Thus, the emotions that were selected were not the most prototypical ones, but it was done in a way to neutralize valence. Indeed, a difference in valence might have been interpreted as a positivity bias rather than as a differential attribution of emotion. Because it is not always easy to find a translation that induces the same meaning as in the original language, here are synonyms and definitions, that can be found in a Spanish dictionary for the words that cannot be exactly translated into English. In Spanish, coraje is associated to an impulsive decision, to anger and irritation. Exaltación is the fact of being overcome by passion.
} 
a member of the ingroup (Canary Islands, Madrid or Barcelona). The other participants filled out the same list for the outgroup (mainland or Canary Islands). Participants were encouraged to choose the traits sparingly.

\section{Results}

\section{Number of Primary and Secondary Emotions}

A 2(participants: low-status Canarians versus high-status Peninsulars) $\times 2$ (target: ingroup versus outgroup) $\times 2$ (emotions: primary versus secondary) ANOVA with the first two factors as betweenparticipants variables and the last as a within-participant variable was conducted on the number of primary and secondary emotions selected by the participants. This number could vary between 0 and 4 .

The only significant main effect concerned the type of emotions, $F(1,257)=21.16, p<0.001$. Secondary emotions $(M=1.39)$ were selected more often than primary ones $(M=1.01)$. The interaction of importance for our purpose involved targets and emotions, and it was significant, $F(1,257)=10.36, p<0.001$. (see Figure 1). As expected, both Canarians and Peninsulars selected more secondary emotions for themselves $(M=1.52)$ than for the outgroup $(M=1.25)$, $F(1,259)=4.05, p<0.05$. While we had no expectation concerning primary emotions, Canarians and Peninsulars attributed more primary emotions to the outgroup $(M=1.14)$ than to the ingroup $(M=0.89), F(1,259)=4.83, p<0.05$.

The interaction between participants and emotions was also significant, $F(1,257)=4.89, p<0.05$. For unknown reasons, Peninsulars selected more primary emotions $(M=1.08)$ than did Canarians $(M=0.94)$ who selected more secondary emotions $(M=1.50)$ than Peninsulars $(M=1.28)$.

The correlations between secondary and primary emotions attributed to the ingroup, $r(128)=0.02$, and to the outgroup, $r(133)=0.01$, were not significant.

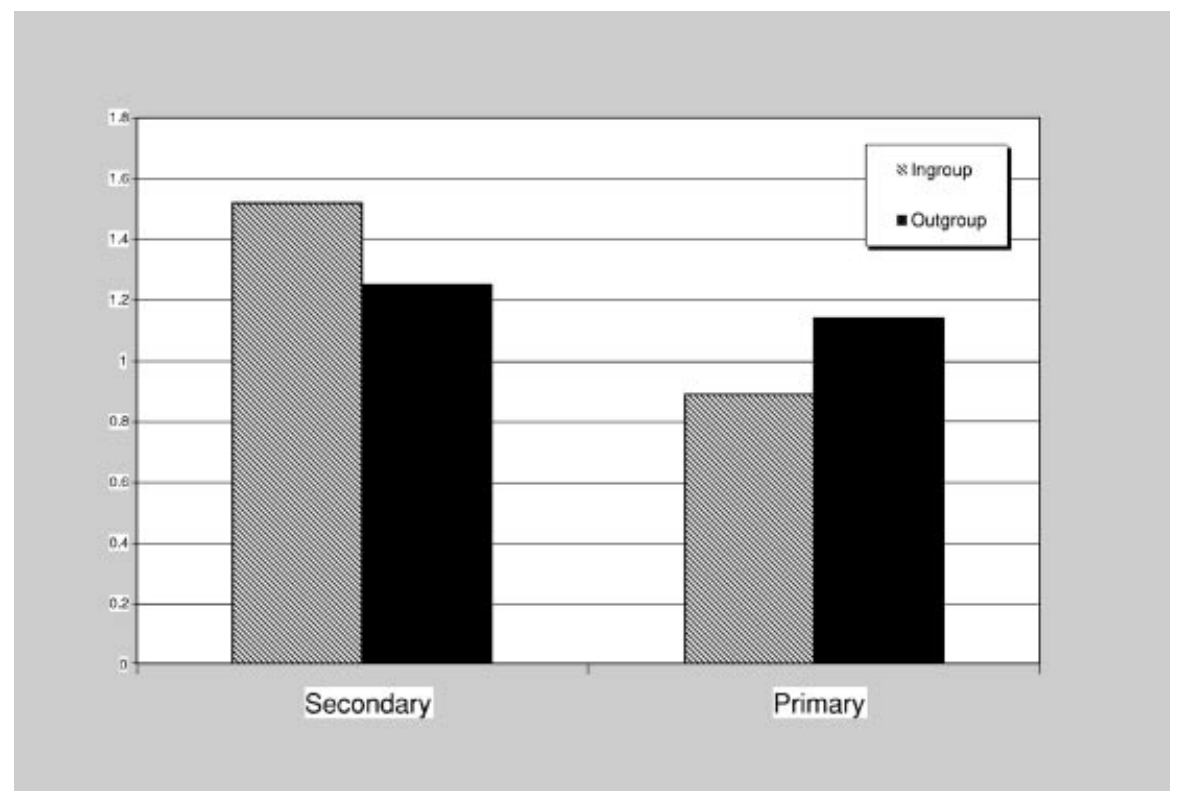

Figure 1. Mean number of primary and secondary emotions attributed to the ingroup and to the outgroup. Study 1 


\section{Discussion}

The present data strongly support our hypotheses. In line with our essentialist approach (Leyens et al., 2000), both Canarians and Peninsulars selected more secondary emotions for their ingroup than for the outgroup, or fewer secondary emotions for the outgroup than for their ingroup. Although unexpected, primary emotions were attributed more often to the outgroup than to the ingroup; we have no explanation for this finding. The higher number of primary emotions attributed to the outgroup than to the ingroup cannot explain the smaller amount of secondary emotions given to the outgroup. Indeed, there was no correlation in the attribution of these two types of emotions.

All the stimuli used in this experiment were positive. If the attribution of secondary emotions to the ingroup reflected a mere positivity effect, it would lose its interest and originality. Could the same results be obtained in the presence of negative stimuli, notwithstanding an ingroup favoritism bias? In particular, would people also select more negative secondary emotions for their ingroup than for the outgroup? A positive answer to these questions would get rid of a simple positivity bias in the case of secondary emotions. It would also be in agreement with our thesis (Leyens et al., 2000) that secondary emotions are uniquely human characteristics and thus are attributed more to the ingroup independent of their valence.

\section{STUDY 2}

Study 2 replicated Study 1 with a few exceptions. This time, the high-status Peninsulars were no longer from Castilla or Cataluna but from Andalucia, or more precisely from Granada. Negative stimuli were also added. For the sake of generalizability, the positive primary and secondary emotions used in Study 2 were different from the ones in Study 1. We hypothesized that people would attribute more positive and negative secondary emotions to their ingroup than to the outgroup. In other words, humanity does not restrict itself to positive secondary emotions but also includes negative ones. If verified, such finding would complement our earlier work on differential associations of primary and secondary emotions (Paladino et al., 1999); indeed, the differential associations occurred for both positive and negative emotions.

\section{Method}

Eighty-seven students from the University of La Laguna and 92 students from the University of Granada took part in the experiment. The procedure was exactly that of Study 1, only the stimuli differed. All the items were pre-tested for valence using a 10-point scale $(1=$ negative and $10=$ positive).

The valence of positive secondary emotions ${ }^{3}$ (felicidad, felicity; deleite, delectation; and disfrute, enjoyment) $(M=8.41)$ and of positive primary emotions (alegría, joy; placer, pleasure; and pasión, passion) $(M=8.28)$ was equal, $t(19)=0.60, n s$. The same was true for negative secondary emotions (melancolía, melancholia; resignación, resignation; and desemparo, disarray) $(M=3.86)$ and for negative primary emotions (aversión, aversion; cólera, anger; and irritación, irritation) $(M=3.55)$, $t(19)=0.79, n s$. The negative stimuli were rated more negatively than the positive ones: $M \mathrm{~s}=3.55$

\footnotetext{
${ }^{3}$ See footnote 2 . Disfrute is the act of perceiving and enjoying the products and utilities of an object. Alegría is the satisfaction of the mind that tends to manifest itself with external signs; it is the state of the person who has abused drinks or other liquors. 
versus $8.28, t(21)=15.42, p<0.001$ for primary emotions; $M \mathrm{~s}=3.86$ versus $8.41, t(21)=14.16$, $p<0.001$ for secondary emotions.

The other words were fillers related to competence and niceness. As in Study 1, their valence was controlled. There was no significant difference between either positive or negative fillers.

\section{Results}

A 2(participants: low-status Canarians versus high-status Peninsulars) $\times 2$ (target: ingroup versus outgroup $) \times 2$ (valence: positive versus negative $) \times 2$ (emotions: primary versus secondary) ANOVA with the first two variables as between-participants factors and the last two as within-participant ones led to a highly significant interaction between target and emotion, $F(1,175)=17.97, p<0.001$. We therefore calculated separate ANOVAs for the number of secondary and primary emotions. This number could vary from 0 to 3 .

\section{Number of Secondary Emotions}

The main effect of importance for our purpose was significant. More secondary emotions were attributed to the ingroup $(M=1.34)$ than to the outgroup $(M=0.88), F(1,175)=39.19, p<0.001$. This effect was not qualified by any interaction. As can be seen from Figure 2, the attribution to the ingroup and the outgroup was not qualified by an interaction involving valence. The main effect of valence was also significant. More positive secondary emotions $(M=1.48)$ were selected than negative ones $(M=0.76), F(1,175)=80.72, p<0.001$. This latter effect is qualified by a significant interaction between participants and valence, $F(1,175)=80.90, p<0.001$. Whereas Canarian students selected an equal number of positive and negative secondary emotions $(M \mathrm{~s}=0.95)$, Peninsular

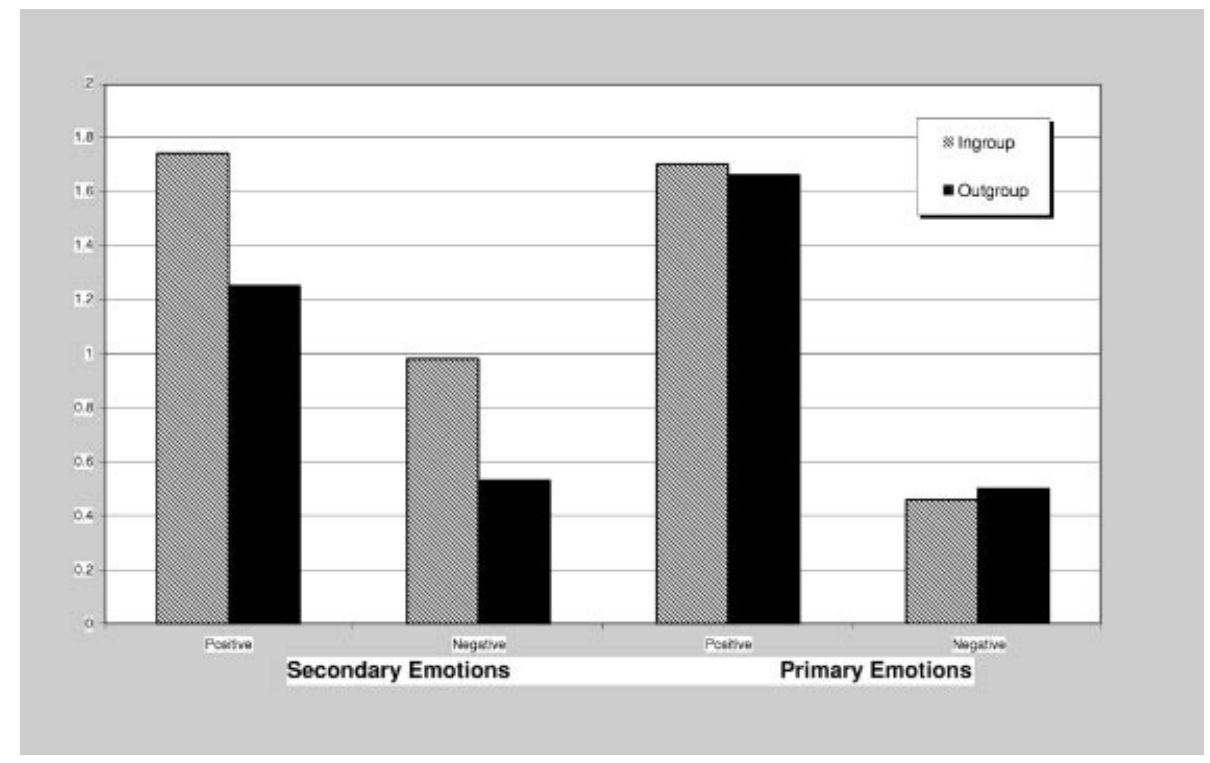

Figure 2. Mean number of positive and negative secondary and primary emotions attributed to the ingroup and to the outgroup. Study 2 
students selected many more positive $(M=2.01)$ than negative $(M=0.57)$ secondary emotions. Finally, there was also a significant main effect of participants. Peninsulars $(M=1.29)$ selected more secondary emotions than did Canarian students $(M=0.95), F(1,175)=20.69, p<0.001$.

\section{Number of Primary Emotions}

Unlike the case for secondary emotions, for primary emotions there was no effect for group. Primary emotions were equally attributed to the ingroup $(M=1.08)$ and to the outgroup $(M=1.07), F(1$, $175)<1, p$. ns. The effect of valence was significant, $F(1,175)=206.32, p<0.001$. More positive $(M=1.68)$ than negative primary emotions $(M=0.48)$ were selected by the participants (see Figure 3$)$. There was also a significant interaction between valence and participants, $F(1,175)=34.84, p<0.001$. Although both Canarians and Peninsulars selected more positive than negative primary emotions, the effect was greater for Peninsulars $(M \mathrm{~s}=2.15$ versus 0.49$)$ than for Canarians ( $M \mathrm{~s}=1.18$ versus 0.48$)$. Finally, there was also a significant second-order interaction which is of no importance for our purpose, $F(1,175)=33.60, p<0.001$. It simply means that the previous interaction between valence and participants was due to the primary emotions selected for the outgroup.

\section{Correlations}

Whereas there was no significant correlation between the number of primary and secondary emotions attributed to the ingroup, $r(87)=0.10, n s$, the correlation was significantly positive for the outgroup, $r(92)=0.25, p<0.02$.

\section{Discussion}

The material of this experiment was very well controlled so that, within each category of stimuli, the positive ones were rated significantly more positive than the negative ones. We also made sure that the valence, positive or negative, did not differ between the different categories of stimuli. Also, the positive primary and secondary emotions differed from those used in Study 1.

The originality of the present experiment was the inclusion of negative emotions in the list provided to the participants. It was especially important for our perspective that participants selected both more positive and negative secondary emotions for their ingroup than for the outgroup. The hypothesis was strongly supported. Significantly more positive and negative secondary emotions were attributed to the ingroup than to the outgroup, irrespective of the origin of the participants. It was not the case of primary emotions, which were distributed equally between the ingroup and the outgroup.

It should be noted that the greater selection of negative secondary emotions to the ingroup than to the outgroup is not contradictory with an ingroup favoritism bias. Both phenomena may co-exist as it is the case in this experiment. Indeed, overall, participants attributed more positive emotions to the ingroup than to the outgroup (see Figure 2).

The data also show a positivity bias (Peeters, 1971; Peeters \& Czapinski, 1990). Indeed, more positive primary and secondary emotions than negative primary and secondary ones were attributed to both the ingroup and the outgroup. This positivity bias is especially due to the Peninsular sample. Compared to the Canarians, Peninsular participants not only selected more primary and secondary emotions, but they also selected more positive ones. We have no explanation for this result.

Although the results for the filler items of this experiment and of Study 1 were not reported, the participants obeyed Fiske et al.'s (1999) taxonomy. The high-status groups saw themselves and were 
seen as competent but not nice. The low-status Canarians saw themselves and were seen as incompetent but nice.

To conclude, this second study supports our main hypothesis that people view both negative and positive secondary emotions as characteristics that define more their ingroup than a disliked outgroup.

\section{STUDY 3}

In the two preceding studies, participants received positive (Study 1) or positive and negative (Study 2) exemplars of primary and secondary emotions that they were free to allocate to the ingroup and the outgroup. To generalize the main finding, that is, the greater attribution of secondary emotions to the ingroup compared to the outgroup, we opted for another paradigm, which does not involve exemplars of specific valence.

This other paradigm was borrowed from Krueger et al. (1989) who used it to investigate category accentuation effects. In Krueger et al.'s (1989) studies, participants had to periodically estimate the cumulative means of each of two sets of numbers. During phase 1, the means of the two sets were mathematically stable. During phase 2, the mean of one set, that is, the focal mean, was modified and the mean of the other set, the contextual mean, remained unchanged. It is the focal mean that is of interest. Indeed, participants are relatively good at calculating the contextual mean whereas they tend to err for the focal one. We were interested to see whether the errors would support our hypothesis.

Krueger et al. (1989; Krueger \& Rothbart, 1990) ran only conditions in which the categories were not personally relevant or involving for the participants. In the present study, the two sets of numbers were given a meaning which had personal relevance to the participants and which was involving or not. The numbers pertained to the ingroup and to the outgroup, a variable of personal relevance, and they represented the degree of calcium, of primary emotions, or of secondary emotions of each group.

According to our theory (Leyens et al., 2000) and the combined results of Studies 1 and 2, the estimates for secondary emotions should vary as a function of the group. The estimated mean should be greater for secondary emotions belonging to the ingroup than for those possessed by the outgroup. Because there is no theoretical reason to attribute different levels of primary emotions to either group, we expected that the estimates for the primary emotions would not differ as a function of the group. Because more primary emotions were attributed to the outgroup than to the ingroup in Study 1, we wanted to reinforce the status of the base-line. Calcium was selected to this effect; indeed, one does not imagine the reason why people would estimate that their group possesses more, or less, calcium than an outgroup.

\section{Method}

\section{Participants}

One hundred and seventy-six students of the University of La Laguna took part in the experiment for partial course credit.

\section{Procedure}

The experiment was conducted in individual sessions that lasted about 50 minutes each. The experimenter presented the study as concerned with the estimation of averages of sequences of 
numbers. She informed the participants that the task was difficult but could be facilitated when people knew the meaning of the numbers. She told the participants that the numbers were based on the scores obtained by different persons who had responded to a questionnaire. According to the conditions, participants were told that the questionnaire dealt with calcium, primary, or secondary emotions. The experimenter explained that they would first have to answer such a questionnaire in order to become familiarized with the concept. In the calcium conditions, participants had to tell the extent to which they used to eat different kinds of food. In the other conditions, the participants had to tell the extent to which they usually felt various positive and negative primary and secondary emotions. After all participants had responded to the questionnaire corresponding to their experimental condition, the experimenter informed them that they would see two categories of numbers. Numbers corresponded to the degree of calcium (or secondary emotion - sentimiento in Spanish, or primary emotion emoción in Spanish) obtained by individuals coming from either the Canary Islands (ingroup) or from the Peninsula (outgroup). To differentiate the two groups, the numbers pertaining to each group were defined by their type of font.

Ninety-six four-digit (two decimals) numbers, comprising 12 blocks of 8 numbers, were presented on personal computers for 2 seconds each. Within each block there were four numbers representing the Canarians and four representing the Peninsulars; the eight numbers were presented in random order. Participants had to type in each number and a letter identifying the category in order to maintain their vigilance. After each block, participants estimated the mean of each category. Participants worked at their own pace but were encouraged to type the numbers, letters, and estimates as quickly as possible.

Each time they made an estimation, participants were instructed to consider all the numbers they had seen up to that point. Hence the task increased in difficulty as the experiment progressed. After the first block, a total of four numbers had been presented for each group (Canarians and Peninsulars); after the second block, the total was eight numbers for each group, and by the end of the experiment, the total was 48 for each group.

\section{Stimulus Material}

Blocks 1 to 6 represented the stable-category phase 1 . The two distributions of 24 numbers in each category were constructed to have a mean difference of 3.60 (i.e. 13.75 versus 17.35). Both distributions were unimodal, symmetrical and had a standard deviation of 1.11. The two distributions bordered each other without overlap. The ingroup was either inferior (i.e. 13.75) or superior (i.e. 17.35) to the outgroup.

Blocks 7 to 12 represented the modified-category phase 2. For one of the categories, the same 24 numbers as in phase 1 were presented in a different random order. For the other category, 16 out of the 24 numbers were increased so that the final mean was 1.20 higher than in phase 1 (i.e. 14.95 versus 18.55). Because Krueger et al. (1989) found more 'errors', that is, accentuation in their case, when the mean difference between the two sets is enhanced rather than reduced, and for the sake of simplicity, we ran only the conditions in which the mean of one of the two sets is increased during phase 2 . Participants were not informed about the difference between the two phases. For half of the participants, the ingroup was represented by the category that changed across the two phases. For the remaining participants, it was the outgroup that changed. Stated otherwise, the ingroup (outgroup) focal mean became either 14.95 or 18.55 during phase 2 , depending on its mean during phase 1 .

\section{Results}

Only the estimates for the focal mean were taken into account in the analyses for the reason explained above. We first calculated a 2 (phases: 1 versus 2 ) $\times 2$ (target: ingroup versus outgroup) $\times 2$ (initial 
position: 13.75 versus 17.35$) \times 3$ (stimuli: calcium versus primary emotions versus secondary emotions) ANOVA with the first variable as within-participant factor and with the latter three as betweenparticipants factors. The only two significant main effects are trivial. Unsurprisingly, the estimates are higher when, by construction, the initial position is 3.60 points higher than the other, $F(1,164)=439.09, p<0.001$. Also, the estimates for phase 2 are higher than during phase 1 because the focal mean has been increased by $1.20, F(1,164)=338.70, p<0.001$. More interesting for our purpose is the significant interaction involving phases, target, and stimuli, $F(2,164)=5.39, p<0.005$. No other interaction was significant.

We then calculated separate 2 (phases: 1 versus 2 ) $\times 2$ (initial position: 13.75 versus 17.35$) \times 3$ (stimuli: calcium versus primary emotions versus secondary emotions) ANOVAs for the ingroup and the outgroup (see Figure 3). Except for the trivial effects of phase and initial position, no other effect was significant as far as the ingroup was concerned. The picture was different for the outgroup. Besides the effects for phase and initial position, the interaction between phase and stimuli was significant, $F(2,79)=4.69, p<0.012$. The estimates for the three stimuli increased, but, as expected, those for the secondary emotions increased least from the first phase $(M=15.00)$ to the second $(M=15.95), F(1,82)=3.75, p<0.05(M \mathrm{~s}=14.28$ versus 16.28 , and 14.49 versus 16.30 , $F(1,82)=7.33, p<0.001$, and $F(1,82)=7.38, p<0.001$ for phases 1 and 2 of primary emotions and calcium, respectively).

We also verified that nothing had happened during phase 1 since the focal mean had not changed during this time (see Figure 3). A 2(target: ingroup versus outgroup) $\times 2$ (initial position: 13.75 versus $17.35) \times 3$ (stimuli: calcium versus primary emotions versus secondary emotions) ANOVA showed the trivial main effect of initial position, $F(1,164)=373.91, p<0.001$. The only other significant effect concerned the target, $F(1,164)=5.08, p<0.03$. In general, estimates were higher for Peninsulars $(M=14.60)$ than for Canarians $(M=14.35)$. We have no explanation for this effect. Importantly, no significant effects involved the stimuli.

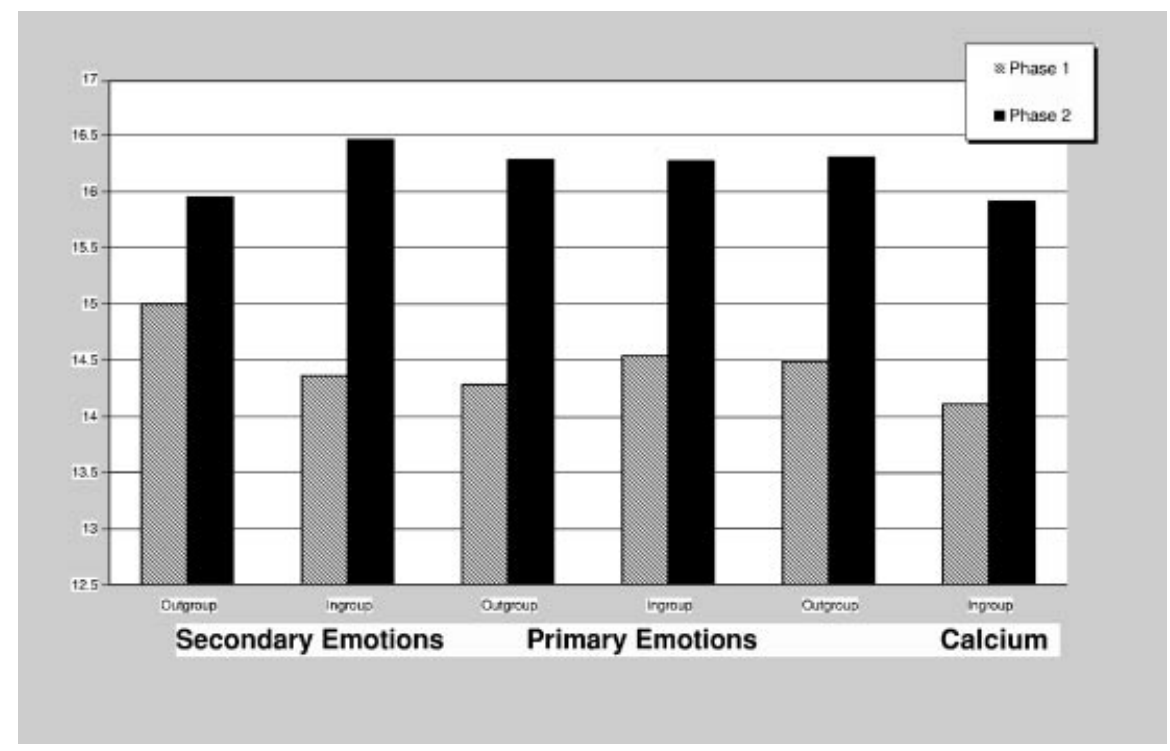

Figure 3. Mean estimations of secondary emotions, primary emotions and calcium for the ingroup and the outgroup. Study 3 


\section{Discussion}

Using another paradigm that did not involve exemplars of primary and secondary emotions, the present results support those obtained in Studies 1 and 2 but give them a special interpretation. Participants in Study 3 estimated on-line the means of calcium, primary, or secondary emotions of their ingroup and of a threatening outgroup (Krueger et al., 1989). When the focal mean was increased during the second part of the experiment, the change of estimates for secondary emotions in the outgroup was smaller than for primary emotions and calcium. This difference seems to indicate a reluctance to give secondary emotions to the outgroup. In Studies 1 and 2, the ingroup received more secondary emotions than the outgroup. According to the results of Study 3, it would be more precise to state that fewer secondary emotions were attributed to the outgroup than to the ingroup. This interpretation is completely in line with the hypothesis of outgroups characterized by a lesser, or incomplete, human essence.

\section{GENERAL DISCUSSION}

The social psychological literature is replete with illustrations of ingroup favoritism biases (for reviews see Brewer \& Brown, 1998; Leyens et al., 1994). Some investigators have proposed that people are fundamentally prejudiced even when they do not explicitly reveal their biases against an outgroup. At the theoretical level, different forms of modern racism (for a review, see Eberhardt \& Fiske, 1998) have been proposed. At the methodological level, implicit measures (Greenwald \& Banaji, 1995) have contributed to the debate by verifying that discrimination and prejudice can take place without people's awareness (for a review, see Dovidio, Kawakami, \& Beach, in press).

\section{Essentialism and Secondary Emotions}

The present paper adds to this literature by adopting a somewhat different theoretical perspective. Groups form social categories to which people tend to attribute an essence (Corneille \& Leyens, 1994; Hirschfeld, 1996; Rothbart \& Taylor, 1992) as they do for natural categories (Medin, 1989). The different essences associated with different groups are supposed to explain why these groups differ. According to an essentialist view, prejudiced individuals explain by a specific essence (genetic, cultural, etc.) such negative stereotypes as laziness, aggressiveness, and lack of intelligence among, for instance, African-Americans or North Africans. Given that individuals are prone to ingroup favoritism, and because people are more concerned with their own group than with outgroups (e.g. Yzerbyt, Castano, Leyens, \& Paladino, 2001; Gaertner, Dovidio, Anastasio, Bachman, \& Rust, 1993), it follows that people attribute 'the' human essence to their own group. Consequently, other groups can only receive an incomplete human essence. Indeed, attributing to one's group the human essence and an infra-human essence to other groups reveals an ingroup-favoritism phenomenon that, impermeably, protects the ingroup from 'impurities'.

Leyens et al. (2000) proposed that the human essence coincides with the uniquely human characteristics. Such characteristics include reasoning, language, and sentiment. The present paper focused on the latter feature. Compared to émotions that correspond to primary emotions common to both humans and animals, sentiments are close to secondary emotions. We hypothesized and tested the idea that ingroup members attribute more secondary emotions to the ingroup than to the outgroup. The 
results of the first two studies clearly supported the hypothesis. In Study 1, members of both a low- and a high-status group selected more secondary emotions for their group than for the outgroup. In Study 2, members of both a low- and a high-status group selected more positive and negative secondary emotions for their ingroup. Study 3 allowed clarifying the meaning of this difference. Indeed, the results of Study 3 seemed to indicate that people deny the possibility of others having secondary emotions.

This interpretation is particularly intriguing and raises the question of the conditions leading to infra-humanization. Indeed, the above results do not mean that people will always attribute fewer secondary emotions to an outgroup than to an ingroup. First, it may be difficult to deny secondary emotions to certain groups (e.g. women). Second, attributing an essence to groups is no more a necessity than being prejudiced against them. To the same extent that groups do not always show ingroup favoritism (e.g. Brown, 1995), they do not ineluctably attribute different essences to various groups. On the other hand, conflict may not be a necessary condition for infra-humanization. Conflict was present in the groups involved in the present three studies, but one may imagine that people will sometimes infra-humanize far-away and unknown groups (e.g. Maoris) with whom they have no relationship. One plausible hypothesis is that people need to identify with their ingroup, and that the comparison with the outgroup has implication for this identification, for infra-humanization to occur. Obviously, further research is needed to clarify such points (for similar views at the individual level, see Goldenberg, Pyszczinski, Greenberg, \& Solomon, 2000).

The perspective adopted in this paper is somewhat similar to the moral exclusion approach (Opotow, 1990; Staub, 1987) except that it does not involve extreme behaviors. Bar-Tal (1989) discussed the notion of delegitimization. According to Bar-Tal, 'Delegitimization is defined as categorization of groups into extreme negative social categories which are excluded from human groups that are considered as acting within the limits of acceptable norms and/or values' (p. 170). Along the same lines, Schwartz and Struch (1989) speak of the 'perceived humanity of the outgroup'. For them, outgroupers 'are assumed to share our humanity to a lesser degree' (p. 154), and this lesser humanity should be reflected in the perception of different hierarchies of values. Indeed, Struch and Schwartz (1989) showed that perceived value dissimilarity mediated aggression towards an outgroup. Also, values such as equality, helpfulness, and honesty typically differentiate the ingroup from an outgroup (Schwartz \& Struch, 1989) and correlate with the willingness for outgroup contacts (Sagiv \& Schwartz, 1995). Although values were never mentioned as uniquely human characteristics by our participants, they probably constitute part of the human essence. This point raises another question: Why are secondary emotions considered uniquely human? Are they, like values, mere signs of refinement or sophistication acquired through learning? In the present set of studies, low-status groups considered that they possessed more secondary emotions than high-status ones whose higher competence was recognized. These results do not favor an explanation in terms of sophistication but the question is certainly not solved and deserves further clarification.

\section{Emotions and Intergroup Relations}

Emotions in intergroup relations have a long history (Guglielmi, 1999). At first, researchers limited themselves to measuring arousal as a reaction to encounters with strangers (Guglielmi, 1999). They then developed dynamic models taking into account anxiety (e.g. Stephan \& Stephan, 1985). Dijker (1987) innovated by investigating which emotions were elicited by specific groups. More recently, Smith $(1993,1999)$ has also pointed to the emotional side of prejudice which produces group-based emotions. While the present approach certainly agrees with an emotional view of prejudice, it also insists on the role played by emotions to differentiate between groups. It assumes that some emotions, that is, secondary emotions, are uniquely human. These uniquely human emotions are part of 
the human essence that groups attribute to themselves and tend to deny to outgroups. As such, uniquely human emotions are not restricted to high-status groups in the society (Jost \& Banaji, 1994; Sidanius \& Pratto, 1999). Their attribution does not depend on structural factors in the society, but on prejudice.

The latter remarks have important theoretical and practical implications. Traditionally, discrimination was studied from the point of view of the members pertaining to dominant groups (see Devine \& Vasquez, 1998, for a similar argument). Such perspective has contributed to enclose minority members in the role of victims whose voice was not even listened to. An increasing number of scholars (e.g. Swim \& Stangor, 1998), however, are turning their attention towards this other part of humankind. It results from their observations that minority members are often less shy than majority members in derogating disliked outgroups. For instance, Sidanius and Pratto (1999) showed that young African Americans discriminated $150 \%$ more in favor of their ingroup than young European Americans did. Judd, Park, Ryan, Brauer, and Kraus (1995) also found more negative stereotypes held by young African Americans towards European Americans than the reverse. Because stereotypes usually vary on the dimensions of competence and likeability (Fiske et al., 1999), they are linked to the existing societal structure and relationship between the groups. For these reasons, they may be difficult to change (Devine \& Elliott, 1995). Emotions, on the contrary, are more flexible.

This flexibility in the hands of both dominant and dominated groups may be a source of optimism as well as of pessimism. It is a source of optimism because a primary emotion (e.g. surprise) may quickly transform itself into a secondary emotion (e.g. astonishment). It is a source of pessimism because both parties may easily deny one another the existence of secondary emotions. In the case of such denial, one is very close to the 'moral exclusion' (Opotow, 1990) or 'delegitimization' (Bar-Tal, 1989) that justifies human-made disasters (Staub, 1989).

\section{ACKNOWLEDGEMENTS}

This research was funded by ARC grant 96/01.198 from the Communauté française de Belgique, and a FRFC 2.4590.00 grant from the Belgian National Fund of Scientific Research to the first author, and by a DGICYT PB98/0433 grant to the second author. We wish to thank Juan Ignacio Aragones, Francisco Elebarietta, and Miguel Moya for helping us to collect data in Madrid, Barcelona, and Granada, respectively. Thanks are also due to Rachel Benn who gathered the Canarian data. Susan Fiske helped greatly in improving a previous draft of this manuscript. Finally, we are grateful to the members of the

Social Psychology Unit, UPSO-UCL, and especially to Nathalie Scaillet, Olivier Corneille, Michel Desert, and Vincent Yzerbyt who discussed this research with us.

\section{REFERENCES}

Allport FH. 1927. The psychology of nationalism: The nationalistic fallacy as a cause of war. Harper's Monthly August; 291-301.

Bar-Tal D. 1989. Delegitimization: The extreme case of stereotyping. In Stereotyping and Prejudice: Changing conceptions, Bar-Tal D, Grauman CF, Kruglanski A, Stroebe W (eds). Springer-Verlag: Berlin.

Bourhis RY, Leyens JPh. 1994. Stéréotypes, discrimination et relations intergroupes. Mardaga: Liège.

Brewer MB. 1991. The social self: on being the same and different at the same time. Personality and Social Psychology Bulletin 17: 475-482.

Brewer MB, Brown RJ. 1998. Intergroup relations. In The Handbook of Social Psychology (Vol. 2) (4th edn), Gilbert DT, Fiske ST, Lindzey G (eds). McGraw-Hill: Boston, MA.

Brown R. 1995. Prejudice: Its Social Psychology. Blackwell: Oxford. 
Buffon G-LL. 1833-1834. Oeuvres Complètes (Vol. 22). Pourrat Frères: Paris.

Campbell DT. 1958. Common fate, similarity, and other indices of the status of aggregates of persons as social entities. Behavioural Sciences 3: 14-25.

Corneille O, Leyens JPh. 1994. Catégories, catégorisation sociale et essentialisme psychologique. In Stéréotypes, discrimination et relations intergroupes, Bourhis RY, Leyens J-Ph (eds). Mardaga: Liège; 42-68.

Crocker J, Major B, Steele C. 1998. Social stigma. In The Handbook of Social Psychology (Vol. 2), Gilbert DT, Fiske ST, Lindzey G (eds). McGraw-Hill: Boston, MA; 504-553.

Devine PG, Elliot AJ. 1995. Are racial stereotypes fading? The Princeton trilogy revisited. Personality and Social Psychology Bulletin 21: 1139-1150.

Devine PG, Vasquez KA. 1998. The rocky road to positive intergroup relations. In Confronting Racism: The problem and the response, Eberhardt JL, Fiske ST (eds). Sage: Thousand Oaks, CA.

Dijker AJ. 1987. Emotional reactions to ethnic minorities. European Journal of Social Psychology 17: 305-325.

Dovidio JF, Kawakami K, Beach KR. in press. Implicit and explicit attitudes: Examination of the relationship between measures of intergroup bias. In Blackwell Handbook on Social Psychology (Vol. 4): Intergroup Relations, Brown R, Gaertner SL (eds). Blackwell: Oxford.

Eberhardt JL, Fiske ST. 1998. Confronting Racism: The problem and the response. Sage: Thousand Oaks, CA. Ekman P. 1992. An argument for basic emotions. Cognition and Emotion 6: 169-200.

Fiske ST, Xu J, Cuddy AJC, Glick PS. 1999. (Dis)respect versus (Dis)liking: Status and interdependence predict ambivalent stereotypes of competence and warmth. Journal of Social Issues 55: 473-489.

Fried M. 1975. The Notion of Tribe. Cummings Publishing: Menlo Park, CA.

Gaertner SL, Dovidio JF, Anastasio PA, Bachman BA, Rust MC. 1993. The common ingroup identity model: Recategorization and the reduction of intergroup bias. In European Review of Social Psychology (Vol. 4), Stroebe W, Hewstone M (eds). Wiley: Chichester; 1-26.

Glick P, Fiske ST. 1999. Sexism and other 'isms': Interdependence, status, and the ambivalent content of stereotypes. In Sexism and Stereotypes in Modern Society: The Gender Science of Janet Taylor Spence, Swann WB Jr, Langlois JH, Gilbert LA (eds). APA: Washington, DC; 193-222.

Goldenberg JL, Pyszczinski T, Greenberg J, Solomon S. 2000. Fleeing the body: A terror management perspective on the problem of human corporeality. Personality and Social Psychology Review 4: 200-218.

Greenwald AG, Banaji MR. 1995. Implicit social cognition: attitudes, self-esteem, and stereotypes. Psychological Review 102: 4-27.

Greenwald AG, McGhee DE, Schwartz JKL. 1998. Measuring individual differences in implicit cognition: The implicit association test. Journal of Personality and Social Psychology 74: 1464-1480.

Guglielmi RS. 1999. Psychophysiological assessment of prejudice: Past research, current status, and future directions. Personality and Social Psychology Review 3: 123-157.

Haslam N, Rothschild L, Ernst D. 2000. Essentialist beliefs about social categories. British Journal of Social Psychology 39: 113-127.

Heine SJ, Lehman DR. 1997. The cultural construction of self-enhancement: An examination of group-serving biases. Journal of Personality and Social Psychology 72(6): 1268-1283.

Hirschfeld LA. 1996. Race in the Making: Cognition, culture, and the child's construction of human kinds. MIT Press: Cambridge, MA.

Johnson-Laird PN, Oatley K. 1989. The language of emotions: An analysis of a semantic field. Cognition and Emotion 3: 81-123.

Jost JT, Banaji MR. 1994. The role of stereotyping in system justification and the production of false consciousness. British Journal of Social Psychology 33: 1-27.

Judd CM, Park B, Ryan CS, Brauer M, Kraus C. 1995. Stereotypes and ethnocentrism: Diverging interethnic perceptions of African American and White American youth. Journal of Personality and Social Psychology 69: 460-481.

Kemper TD. 1987. How many emotions are there? Wedding the social an automatic components. American Journal of Sociology 93(2): 263-289.

Krueger J, Rothbart M. 1990. Contrast and accentuation effects in category learning. Journal of Personality and Social Psychology 59: 651-663.

Krueger J, Rothbart M, Sriram N. 1989. Category learning and change: Differences in sensitivity to information that enhances or reduces intercategory distinctions. Journal of Personality and Social Psychology 56: 866-875.

Lévi-Strauss C. 1952/1987. Race et Histoire. Denoël: Paris.

Leyens JPh, Paladino MP, Rodriguez RT, Vaes J, Demoulin S, Rodriguez AP, Gaunt R. 2000. The emotional side of prejudice: the role of secondary emotions. Personality and Social Psychology Review 4(2): 186-197. 
Leyens JPh, Yzerbyt VY. 1992. The ingroup overexclusion effect: Impact of valence and confirmation on stereotypical information search. European Journal of Social Psychology 22: 549-569.

Leyens JPh, Yzerbyt VY, Schadron G. 1994. Stereotypes and Social Cognition. Sage: London.

Medin DL. 1989. Concepts and conceptual structure. American Psychologist 44: 1469-1481.

Miller DT, Prentice DA. 1999. Some consequences of a belief in group essence: The category divide hypothesis. In Cultural Divides: Understanding and Overcoming Group Conflict, Prentice DA, Miller DT (eds). Russel Sage Foundation: New York; 213-238.

Opotow S. 1990. Moral exclusion and injustice: An introduction. Journal of Social Issues 46(1): 173-182.

Peeters G. 1971. The positive-negative asymmetry: On cognitive consistency and positivity bias. European Journal of Social Psychology 1: 455-474.

Peeters G, Czapinski J. 1990. Positive-negative asymmetry in evaluations: The distinction between affective and informational negativity effects. In European Review of Social Psychology (Vol. 1), Hewstone M, Stroebe W (eds). Wiley: Chichester; 33-60.

Plutchik R. 1994. The Psychology and Biology of Emotion. HarperCollins College Publishers: New York.

Rothbart M, Taylor M. 1992. Category labels and social reality: Do we view social categories as natural kinds? In Language, Interaction and Social Cognition, Semin G, Fiedler F (eds). Sage: London.

Sagiv L, Schwartz SH. 1995. Value priorities and readiness for out-group social contact. Journal of Personality and Social Psychology 69: 437-448.

Schatz RT, Staub E. 1997. Manifestations of blind and constructive patriotism: Personality correlates and individual-group relations. In Patriotism: In the lives of individuals and nations, Bar-Tal D, Staub E (eds). Nelson-Hall Publishers: Chicago, IL; 229-245.

Schwartz SH, Struch N. 1989. Values, stereotypes, and intergroup antagonism. In Stereotyping and Prejudice: Changing conceptions, Bar-Tal D, Grauman CF, Kruglanski A, Stroebe W (eds). Springer-Verlag: Berlin.

Sears DO. 1988. Symbolic racism. In Eliminating Racism: Profiles in Controversy. Perspectives in Social psychology, Katz PA, Taylor DA et al. (eds). Plenum Press: New York; 53-84.

Shanklin E. 1994. Anthropology and Race. Wadsworth: Belmont, CA.

Sherif M, Sherif CW. 1964. Reference Groups. Harper and Row: New York.

Sidanius J, Pratto F. 1999. Social Dominance: An intergroup theory of social hierarchy and oppression. Cambridge University Press: New York.

Smith ER. 1993. Social identity and social emotions: Toward new conceptualizations of prejudice. In Affect, Cognition, and Stereotyping, Mackie DM, Hamilton DL (eds). Academic Press: New York; 297-315.

Smith ER. 1999. Affective and cognitive implications of a group becoming part of the self: New models of prejudice and of the self-concept. In Social Identity and Social Cognition, Abrams D, Hogg MA (eds). Blackwell: Oxford; 183-196.

Sroufe AL. 1979. Socioemotional development. In Handbook of Infant Development, Osofsky JD (ed.). Wiley: New York; 462-516.

Staub E. 1987. Commentary on part 1. In Empathy and its Development. Cambridge Studies in Social and Emotional Development, Eisenberg N, Strayer J et al. (eds). Cambridge University Press: New York; 103-115.

Staub E. 1989. The Roots of Evil: The origins of genocide and other group violence. Cambridge University Press: Cambridge.

Stephan WD, Stephan CW. 1985. Intergroup anxiety. Journal of Social Issues 41: 151-175.

Struch N, Schwartz SH. 1989. Intergroup aggression: Its predictors and distinctness from in-group bias. Journal of Personality and Social Psychology 56: 364-373.

Swim JK, Stangor C. 1997. Prejudice: The target's perspective. Academic Press: New York.

Yzerbyt VY, Castano E, Leyens JPh, Paladino MP. 2001. The primacy of the ingroup: The interplay of entitativity and identification. European Review of Social Psychology 11: 257-295.

Yzerbyt VY, Leyens JPh, Bellour F. 1995. The ingroup overexclusion effect: Identity concerns in decision about group membership. European Journal of Social Psychology 25: 1-16.

Yzerbyt V, Rocher S, Schadron G. 1997. Stereotypes as explanations: A subjective essentialist view of group perception. In The Psychology of Stereotyping and Group Life, Spears R, Oakes P, Ellemers N, Haslam SA (eds). Blackwell: Oxford; 20-50. 
Copyright of European Journal of Social Psychology is the property of John Wiley \& Sons Inc. and its content may not be copied or emailed to multiple sites or posted to a listserv without the copyright holder's express written permission. However, users may print, download, or email articles for individual use. 
Copyright of European Journal of Social Psychology is the property of John Wiley \& Sons, Inc. and its content may not be copied or emailed to multiple sites or posted to a listserv without the copyright holder's express written permission. However, users may print, download, or email articles for individual use. 